05

\title{
Экспериментальное определение механических свойств анодного элемента рентгеновского литографа
}

\author{
( Н.А. Дюжев, Е.Э. Гусев, А.А. Дедкова, Д.А. Товарнов, М.А. Махиборода \\ Национальный исследовательский университет „МИЭТ“, \\ 124498 Москва, Россия \\ e-mail: bubbledouble@mail.ru
}

Поступило в Редакцию 2 апреля 2020 г.

Принято к публикации 2 апреля 2020 г.

В окончательной редакции 2 апреля 2020 г.

Изготовлен анодный элемент рентгеновского литографа в виде мембранной структуры $\mathrm{PolySi} / \mathrm{Si}_{3} \mathrm{~N}_{4} / \mathrm{SiO}_{2}$ по групповой технологии. Модернизирована конструкция стенда для определения механических свойств мембран. Критическое давление мембранной структуры диаметром $250 \mu \mathrm{m}$ изменялось в диапазоне от 0.484 до $0.56 \mathrm{MPa}$ для 15 образцов. Механическая прочность структуры $\mathrm{PolySi} / \mathrm{Si}_{3} \mathrm{~N}_{4} / \mathrm{SiO}_{2}$ составила $3.13 \mathrm{GPa}$. Новая модель в пакете Comsol показала хорошую корреляцию между экспериментальным критическим давлением и теоретической механической прочностью мембраны. Представлено распределение механических напряжений по мембране посредством моделирования и аналитического расчета. Доказано, что область разрыва структуры локализована на границе мембрана/подложка.

Ключевые слова: механическая прочность, мембраны, тонкие пленки, поликристаллический кремний, оксид кремния, нитрид кремния.

DOI: $10.21883 /$ JTF.2020.11.49971.107-20

\section{Введение}

Десятикратное превышение дифракционного предела рабочей длины волны литографа $193 \mathrm{~nm}$ приводит к увеличению стоимости процесса и оборудования [1]. Вариант использования проекционной фотолитографии в глубоком ультрафиолете (EUV-литографии) с рабочей длиной волны $13.5 \mathrm{~nm}$ [2] при формировании критических размеров на чипе обладает недостаточной производительностью. Одним из возможных решений является безмасочная рентгеновская нанолитография [3], которая потенциально обладает высокой производительностью. В качестве источника рентгеновского излучения в литографе может быть рассмотрена рентгеновская трубка, включающая в себя катод и прострельный анод. Исследованию механических свойств прострельного анодного элемента посвящена настоящая работа (рис. 1). Анодный элемент должен выдерживать вакуумную атмосферу (избыточное давление в $0.1 \mathrm{MPa)}$ рентгеновской трубки и обладать достаточной рентгенопрозрачностью за счет малой толщины материала в области мембраны. В качестве элемента мишени выбран материал поликремния, который позволяет сгенерировать волну длиной $13.5 \mathrm{~nm}$. Слои $\mathrm{SiO}_{2}$ и $\mathrm{Si}_{3} \mathrm{~N}_{4}$ обладают сжимающими и растягивающими механическими напряжениями, что приводит к компенсации напряжений и повышению запаса механической прочности.

Одной из проблем в процессе разработки приборов электроники на основе кремния является достоверность сведений о механической прочности материалов [4], особенно с учетом размерного эффекта между объемными и пленочными материалами [5].
Поэтому необходимо совершенствовать метрологическую базу измерений. В работе [6] механическая прочность боросиликатного стекла измерена методом ударного сжатия. В работе [7] механическая прочность слоя нитрида галлия, сформированного методом гидриднохлоридной парофазной эпитаксии, определена посредством индентора. В настоящей работе авторы применяли бесконтактный метод выдувания тонкой пленки посредством избыточного давления, к достоинствам которого можно отнести отсутствие внесенных дефектов.

В настоящее время совершенствуются технологические подходы повышения механической прочности. Например, переходят от прямоугольной к круглой форме

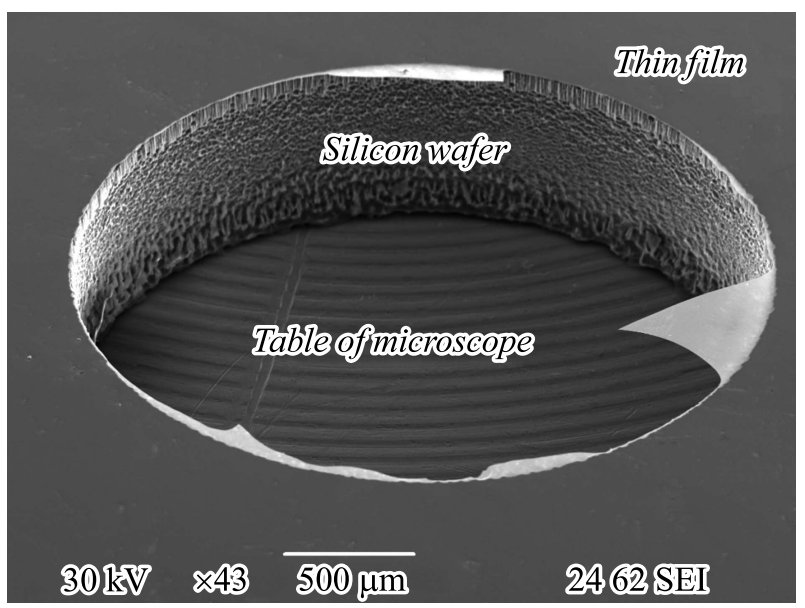

Рис. 1. Недостаток механической прочности тонкопленочной мембраны. 
мембраны [8]. Это связано с тем, что разрушение мембраны в большинстве случаев происходит по границе мембрана-подложка. Форма круга обеспечивает значительно меньшие значения упругих деформаций по сравнению с прямоугольной формой мембраны. Значения деформаций равномерно распределены по контуру мембраны и в материале мембраны [8]. Известен метод увеличения механической прочности, заключающийся в изменении стехиометрического соотношения между атомами в материале, например увеличение концентрации углерода в $\mathrm{SiC}$ [9]. К другим факторам повышения механической прочности относят: уменьшение поверхностных дефектов [10], изменение размера зерен структуры [11], легирование материала пленки атомами меди, цинка, магния, марганца, кремния [5].

\section{1. Изготовление структуры}

Использовали пластину из монокристаллического кремния КДБ12 диаметром 150 mm с кристаллографической ориентацией (100) и толщиной $670 \mu \mathrm{m}$. Была сформирована круглая мембрана на Si кристалле квадратной формы со стороной $6 \mathrm{~mm}$. Исследуемая мембранная структура состоит из верхнего слоя поликристаллического кремния толщиной $0.8 \pm 0.05 \mu \mathrm{m}$, слоя нитрида кремния толщиной $0.13 \pm 0.02 \mu \mathrm{m}$, и нижнего диэлектрического слоя оксида кремния толщиной $0.5 \pm 0.1 \mu \mathrm{m}$ (рис. 2). Топология набора мембран представляет собой круг диаметром $0.25 \mathrm{~mm}$, расположенный по центру кристалла. В мембране отсутствуют концентраторы механических напряжений за счет использования шаблона травления круглой формы.

\section{2. Анализ механической прочности структуры}

В следующих работах указан диапазон значений механической прочности пленки оксида кремния: от 1.2 до $1.9 \mathrm{GPa}$ PECVD оксида кремния [12]; $0.364 \pm 0.057 \mathrm{GPa}$

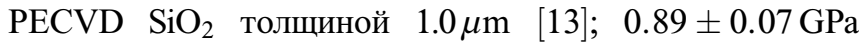
термического $\mathrm{SiO}_{2}$ для слоев толщиной от 507 до $985 \mathrm{~nm}$ [14]; $8.4 \mathrm{GPa}$ для нитевидных структур из $\mathrm{SiO}_{2}$ [15]. Значение механической прочности пленки нитрида кремния составляет $14.0 \mathrm{GPa}$ [15-17]. В книге 2018 г. [18] указано, что механическая прочность пленки нитрида кремния, полученной методом LPCVD, изменяется в диапазоне от 10.8 до $11.7 \mathrm{GPa}$, при толщине пленки от 72.6 до $83.4 \mathrm{~nm}$. По результатам работы [19] механическая прочность LPCVD нитрида кремния составляет $5.87 \mathrm{GPa}$. В процессе анализа литературы были найдены следующие значения механической прочности тонких слоев поликристаллического кремния: от 1.8 до $3.7 \mathrm{GPa}$ в зависимости от размера зерен [20], $8.11 \pm 0.31 \mathrm{GPa}[21], 1.7 \pm 0.5 \mathrm{GPa}$ для площади поверхности $225 \mu \mathrm{m}^{2}, 1.3 \pm 0.3 \mathrm{GPa}$ для $1100 \mu \mathrm{m}^{2}$ и $0.6 \pm 0.2 \mathrm{GPa}$ для $8600 \mu \mathrm{m}^{2}$ [22], 1-1.2 GPa [23],

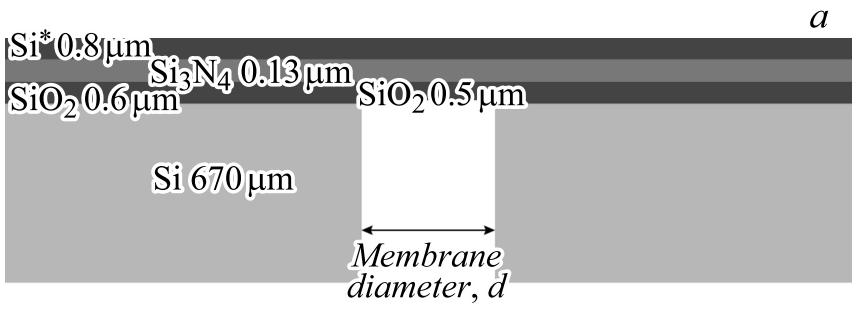

$b$

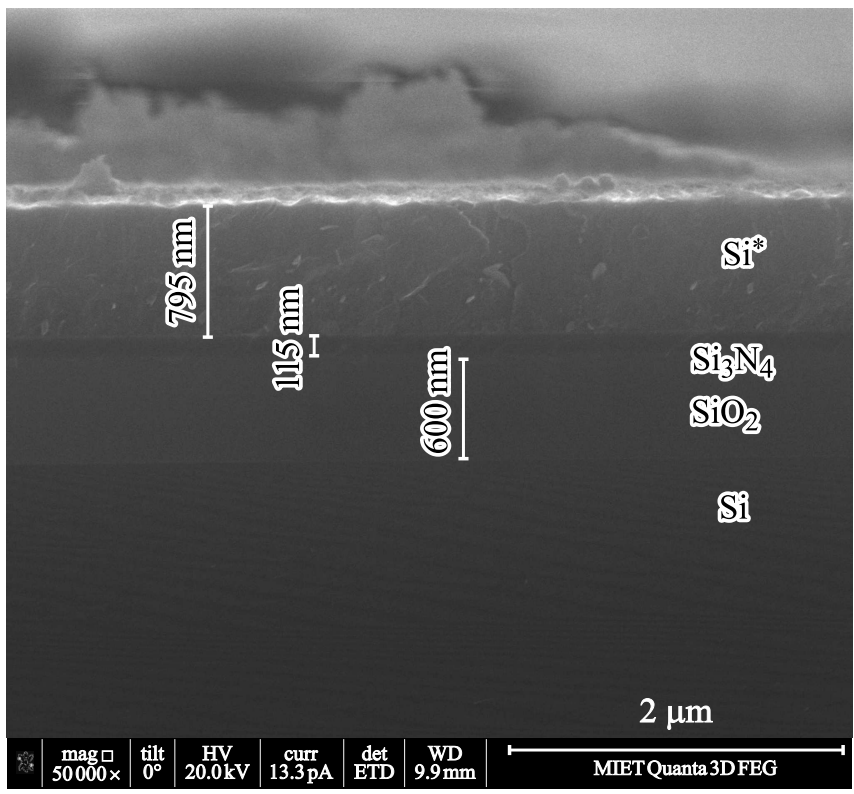

Рис. 2. Исследуемая структура: $a-$ общий вид, $b-$ срез структуры в области тонкой пленки.

$3.15 \pm 0.69 \mathrm{GPa}$ [24], от 0.8 до $1.1 \mathrm{GPa}$ [25], от 1.0 до $1.5 \mathrm{GPa}$ [26]. Для дальнейших расчетов было использовано значение механической прочности поликристаллического кремния $1.8 \mathrm{GPa}$, оксида кремния $0.365 \mathrm{GPa}$ и нитрида кремния $14 \mathrm{GPa}$.

Теоретическое значение механической прочности (максимальных механических напряжений) мембраны $\sigma_{\text {т }}$ вычисляется по формуле:

$$
\sigma_{\mathrm{T}}=\frac{\sigma_{\mathrm{Poly} \mathrm{Si}} h_{\mathrm{Poly} \mathrm{Si}}+\sigma_{\mathrm{SiO}_{2}} h_{\mathrm{SiO}_{2}}+\sigma_{\mathrm{Si}_{3} \mathrm{~N}_{4}} h_{\mathrm{Si}_{3} \mathrm{~N}_{4}}}{h_{\text {Poly Si }}+h_{\mathrm{SiO}_{2}}+h_{\mathrm{Si}_{3} \mathrm{~N}_{4}}},
$$

где $h_{\mathrm{Poly} \mathrm{Si}}$ - толщина слоя поликристаллического кремния, $h_{\mathrm{SiO}_{2}}$ - толщина оксида кремния, $h_{\mathrm{Si}_{3} \mathrm{~N}_{4}}-$ толщина слоя нитрида кремния.

Рассчитанное значение $\sigma_{\text {т }}$ составляет $3.2 \mathrm{GPa}$. Распределение механических напряжений по диаметру мембраны рассчитывается по формуле [5]:

$$
\begin{aligned}
& \sigma=\frac{3 P}{8 h^{2}} \\
& \times \sqrt{\left((1+\mu)^{2}\left(2 a^{4}-8 a^{2} r^{2}\right)+r^{4}\left(10+12 \mu+10 \mu^{2}\right)\right)},
\end{aligned}
$$

где $a$ - радиус мембраны, $h$ - толщина мембраны, $P$ - давление на мембрану, $\mu$ - коэффициент Пуассона мембраны, $r$ - расстояние от центра мембраны. 
Результаты расчета по формуле (2) распределения механических напряжений по диаметру мембраны показаны на рис. 3, $a$. Согласно аналитическому расчету, максимальные механические напряжения $\sigma_{\max }$ возникают, когда расстояние от центра (середины) мембраны равно радиусу, т.е. $r=a$. Таким образом, прогнозируемое значение критического избыточного давления $P_{c r}$ рассчитывают по формуле (3) [5]:

$$
P_{c r}=\frac{\sigma_{\max } h^{2}}{a^{2} B(\mu)} \text {. }
$$

Коэффициент $B(\mu)$ рассчитывается как $\frac{3}{4} \sqrt{1+\mu^{2}}$. Значение коэффициента Пуассона мембраны $\mu$ рассчитывается аналогично подходу в формуле (1). Учитывая, что $\mu_{\text {Рoly Si }}$ составляет $0.22, \mu_{\mathrm{SiO}_{2}}$ составляет $0.2, \mu_{\mathrm{Si}_{3} \mathrm{~N}_{4}}$ составляет 0.23 , то коэффициент Пуассона мембраны $\mu$ будет равным 0.21. Следовательно, значение коэффициента $B(\mu)$ составляет 0.76. Таким образом, согласно расчетам по формуле (2) для мембраны диаметром $0.25 \mathrm{~mm}$ прогнозируемое значение критического избыточного давления $P_{c r}$ составляет $0.554 \mathrm{MPa}$.

Также была составлена модель в среде Comsol Multiphysics. Координаты области подложки от -325
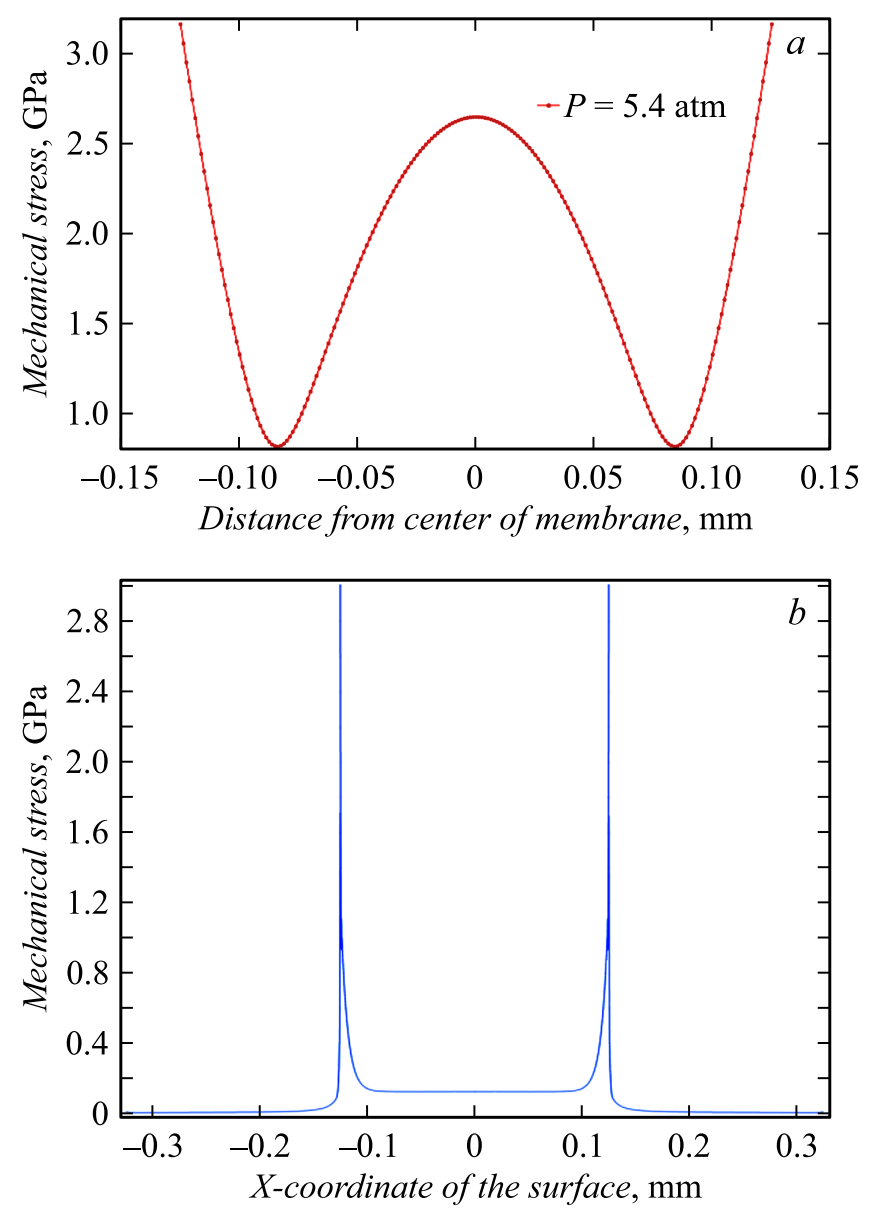

Рис. 3. Распределение механических напряжений в мембране диаметром $0.25 \mathrm{~mm}$ : $a-$ расчет по формуле при $P=5.4 \mathrm{~atm}$; $b$ - моделирование при $P=5.4 \mathrm{~atm}$.

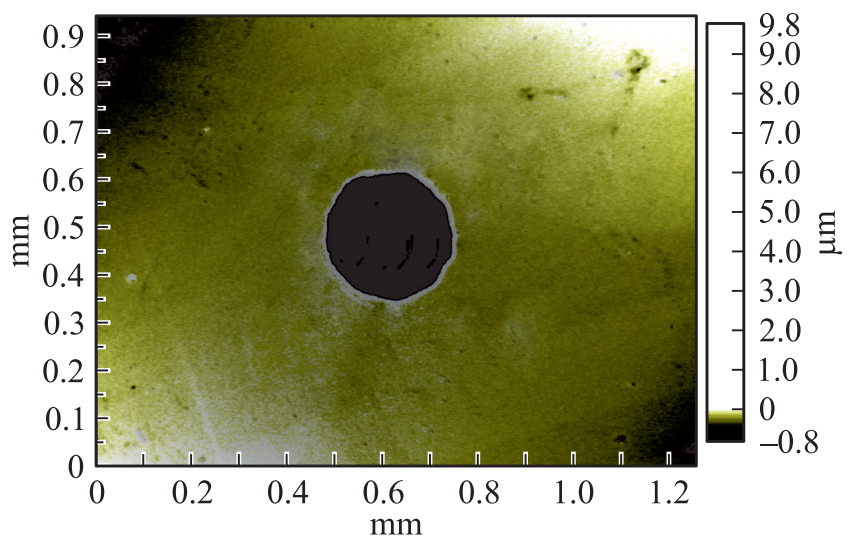

Рис. 4. Вид сверху на структуру после разрыва.

до $-125 \mu \mathrm{m}$ и от 125 до $325 \mu \mathrm{m}$ по оси $X$. Область мембраны расположена симметрично относительно координаты оси $X=0$. В области мембраны была выбрана прямоугольная сетка, в которой 1040 элементов по оси $X$ и 22 элемента по оси $Y$ (каждый слой пленки разделен на 10 элементов, а слой $\mathrm{Si}_{3} \mathrm{~N}_{4}$ на 2 в силу величины толщины слоя). В области кремниевой подложки выбран свободный треугольный тип сетки. Получена зависимость распределения механических напряжений мембраны диаметром $0.25 \mathrm{~mm}$ и в тонкой пленке при избыточном давлении $0.54 \mathrm{MPa}$ (рис. $3, b$ ), полученном из экспериментальных данных. Характер распределения напряжений в области мембраны совпадает с результатами, приведенными в работе 2020 г. [4].

Максимум механических напряжений локализован на границе мембрана/подложка. Разработанная модель в среде Comsol хорошо коррелирует (относительная погрешность $0.25 \%$ ) с экспериментальными и теоретическими данными, так как при избыточном давлении $0.54 \mathrm{MPa}$ максимальное значение механических напряжений составляет $3.17 \mathrm{GPa}$. Наблюдается отсутствие материала мембраны в полости кремния на изображении структуры после критической деформации мембраны (рис. 4). Таким образом, мембрана разрывается по границе мембрана/подложка.

\section{3. Анализ двухосного модуля упругости структуры}

Анализируя зависимость (формула (4)) прогиба мембраны $w$ от избыточного давления $P$, можно определить двухосный модуль упругости $E /(1-\mu)$ :

$$
P=C_{1} \frac{\sigma_{0} h w}{a^{2}}+C_{2} \frac{E h w^{3}}{(1-\mu) a^{4}},
$$

где $P$ - избыточное давление, $\sigma_{0}$ - остаточные механические напряжения в структуре при $P=0, h-$ толщина мембраны, $w$ - прогиб мембраны, $a$ радиус мембраны, $E$ - модуль Юнга, $\mu$ - коэффициент Пуассона. 
Значения коэффициентов $C_{1}$ и $C_{2}$ зависят от формы мембраны. Обычно при работе с круглыми мембранами используют $C_{1}=4$ и $C_{2}=8 / 3$. Зависимость $P(w)$ можно разделить на крутую и пологую область. Критерий крутой области выполняется при малых значениях прогиба мембраны $w$, т. е. первое слагаемое значительно больше второго. Значение двуосного модуля упругости $E /(1-\mu)$ вычисляют на пологой области зависимости (4) при больших значениях прогиба мембраны $w$, т.е. значением первого слагаемого можно пренебречь (формула (5)):

$$
\frac{E}{1-\mu}=\frac{P a^{4}}{C_{0} h w^{3}} .
$$

Модуль Юнга нитрида кремния составляет $225 \mathrm{GPa}$ [19], модуль Юнга оксида кремния составляет $60.1 \pm 3.4 \mathrm{GPa}[13]$, а модуль Юнга поликристаллического кремния $155 \mathrm{GPa}[16,20]$. Следовательно, модуль Юнга мембраны составляет $128 \mathrm{GPa}$. Теоретическое значение двуосного модуля упругости мембраны $E /(1-\mu)$ составит $162 \mathrm{GPa}$ при коэффициенте Пуассона мембраны $\mu$ равном 0.21 рассчитанном ранее.

Ниже представлена зависимость максимального прогиба мембраны от избыточного давления (рис. 5). В формуле (4) величина остаточных напряжений в структуре составляет $100 \mathrm{MPa}$. Для повышения корреляции между расчетом по формуле (4), моделированием в среде Comsol и экспериментальными данными величина начального прогиба (при $P=0$ ) составляет $4.5 \mu \mathrm{m}$ при моделировании и в аналитическом расчете, также величина двуосного модуля упругости $E /(1-\mu)$ составляет $85 \mathrm{GPa}$.

Из рис. 5 можно сделать несколько выводов. Относительная погрешность формулы с экспериментальными данными составляет $3.24 \%$, а относительная погрешность моделирования с экспериментальными данными составляет $3.02 \%$. Исходная структура имеет значительную величину прогиба мембраны, которая не учитывается в исходной формуле и в модели Comsol. Рассчитывая

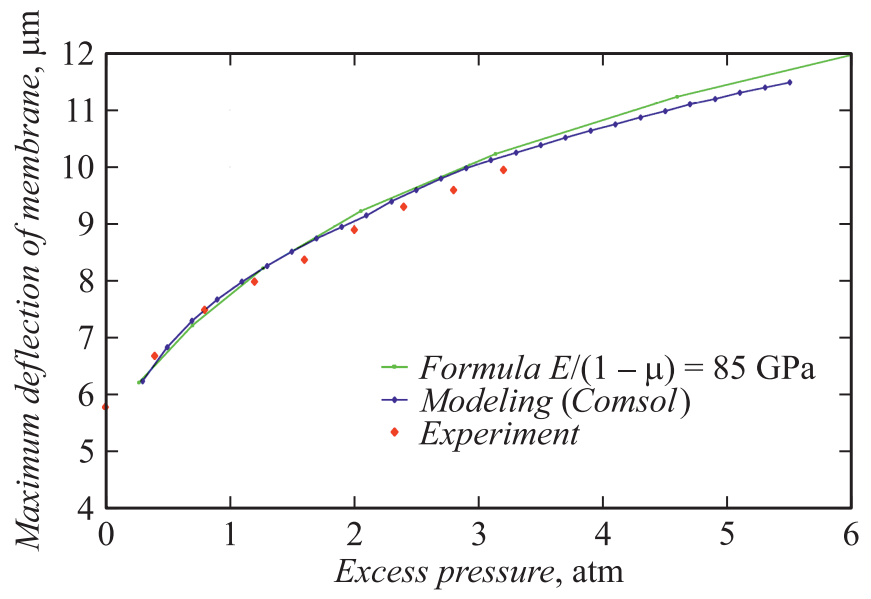

Рис. 5. Зависимость максимального прогиба мембраны от избыточного давления для диаметра $0.25 \mathrm{~mm}$.

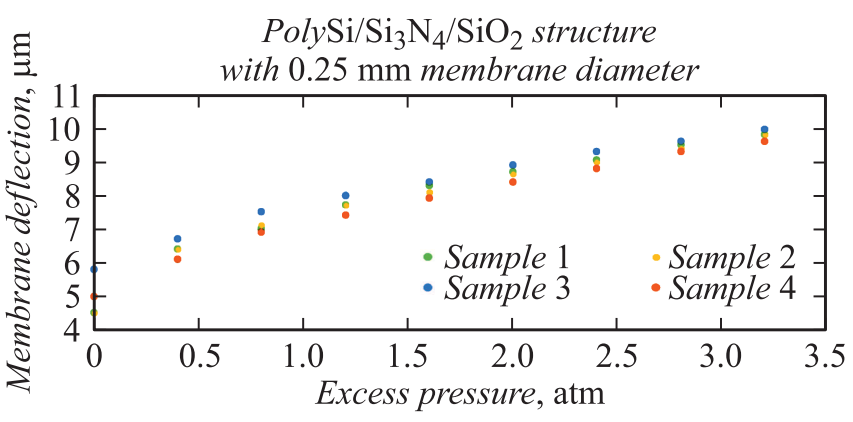

Рис. 6. Экспериментальная зависимость прогиба мембраны от избыточного давления.

по формуле (5) модуль упругости из экспериментальных данных при давлении $P$, равном $0.32 \mathrm{MPa}$, получим значение $20 \mathrm{GPa}$, что в несколько раз меньше теоретического значения. Это может быть связано с тем, что экспериментально измеренный массив значений $w(P)$ расположен в крутой области зависимости (4). Следовательно, необходимо разрабатывать оснастки для защиты профилометра от материала взрывающейся мембраны во время сканирования. Это позволит получить больший массив данных $w(P)$, что приведет к повышению точности определения двуосного модуля упругости.

\section{4. Экспериментальное измерение механической прочности}

Для определения механических свойств мембранных элементов был модернизирован ранее разработанный стенд [5]. Избыточное давление подается с магистрали (вместо компрессора). Таким образом, расширен верхний диапазон величины давления до $0.65 \mathrm{MPa}$, увеличена стабильность значения давления в системе.

Были экспериментально определены значения критического избыточного давления на модернизированном стенде. При диаметре $0.25 \mathrm{~mm}$ механическая прочность мембраны PolySi $/ \mathrm{Si}_{3} \mathrm{~N}_{4} / \mathrm{SiO}_{2}$ составляет $0.52 \pm 0.04 \mathrm{MPa}$ для диаметра $0.25 \mathrm{~mm}$ (15 образцов). Заметно, что полученные результаты обладают высокой воспроизводимостью. Экспериментальное значение механической прочности трехслойной мембраны составляет $3.13 \mathrm{GPa}$.

В процессе проведения эксперимента при избыточных давлениях более $0.32 \mathrm{MPa}$ прогиб мембраны не измерялся (рис. 6). Ограничение связано с защитой дорогостоящего объектива профилометра от материала разрывающейся мембраны. Разрыв мембраны может произойти в процессе сканирования поверхности образца профилометром.

\section{Выводы}

Экспериментальное значение механической прочности трехслойной мембраны $\mathrm{PolySi} / \mathrm{Si}_{3} \mathrm{~N}_{4} / \mathrm{SiO}_{2}$ составляет $3.13 \mathrm{GPa}$, двуосный модуль упругости $E /(1-u)$ 
составляет $20 \mathrm{GPa}$. Критическое избыточное давление мембранных структур из $\mathrm{PolySi} / \mathrm{Si}_{3} \mathrm{~N}_{4} / \mathrm{SiO}_{2}$ на кремниевой подложке составляет $0.52 \pm 0.04 \mathrm{MPa}$ для диаметра $0.25 \mathrm{~mm}$. Полученный результат позволяет использовать данные мембраны в качестве анодов рентгеновских источников прострельного типа с запасом механической прочности в несколько раз. Повышение механической прочности объясняется эффектом использования набора слоев вместо монослоя мембраны; эффектом повышения механической прочности пленок за счет модернизации технологии осаждения.

\section{Финансирование работы}

Работы выполнены на оборудовании ЦКП „МСТ и ЭКБ“ НИУ МИЭТ при поддержке Минобрнауки РФ (ГК № 14.581.21.0021, УH RFMEFI58117Х0021).

\section{Конфликт интересов}

Авторы заявляют, что у них нет конфликта интересов.

\section{Список литературы}

[1] Дюжев Н.А., Демин Г.Д., Пестов А.Е., Салащенко Н.Н., Чхало Н.И. // Микроэлектроника-2019. С. 429.

[2] $W u$ B., Kumar A. // Appl. Phys. Rew. 2014. Vol. 1. N 1. DOI: $10.1063 / 1.4863412$

[3] Chkhalo N.I., Lopatin A.Ya., Pestov A.E., Salashchenko N.N., Gemin G.D., Dyuzhev N.A., Makhiboroda M.A. // Proc. SPIE. 2019. Vol. 110221M. DOI: $10.1117 / 12.2522105$

[4] Шиейзман В.В., Николаев В.И., Поздняков А.О., Бобыль А.В., Тимашов Р.Б., Аверкин А.И. // ЖТФ. 2020. T. 90. Вып. 1. С. 79-84. [SHpejzman V.V., Nikolaev V.I., Pozdnyakov A.O., Bobyl' A.V., Timashov R.B., Averkin A.I. // Tech. Phys. 2020. Vol. 90. N 1. P. 79-84. DOI: $10.21883 / J T F .2020 .01 .48665 .148-19]$

[5] Gusev E.E., Borisova A.V., Dedkova A.A., Salnikov A.A., Kireev V.Y. // 2019 IEEE Conference of Russian Young Researchers in Electrical and Electronic Engineering (EIConRus). 2019. № 8657243. P. 1990-1994. DOI: $10.1109 /$ eiconrus.2019.8657243

[6] Савиных А.С., Канель Г.И., Разоренов С.В. // ЖТФ. 2010. Т. 80. Вып. 6. [Savinykh A.S., Kanel G.I., Razorenov S.V. // Tech. Phys. 2010. Vol. 55. N 6. P. 839 843. DOI: $10.1134 / \mathrm{S} 1063784210060150]$

[7] Жиляев Ю.В., Раевский С.Д., Грабко Д.З., Леу Д.С., Компан М.Е., Юсупова Ш.А., Щеглов М.П. // Письма в ЖТФ. 2005. T. 31. Вып. 9. C. 20-25. [Zhilyaev Y.V., Raevskii S.D., Grabko D.Z., Leu D.S., Kompan M.E., Yusupova S.A., Shcheglov M.P. // Tech. Phys. Lett. 2005. Vol. 31. N 5. P. 367369. DOI: $10.1134 / 1.1931770]$

[8] Vlasov A., Civinskaya T., Shahnov A. // MES-2016. 2016.

[9] Шикунов С.Л., Курлов В.Н. // ЖТФ. 2017. Т. 87. Вып. 12. C. 1871-1878. [Shikunov S.L., Kurlov V.N. // Tech. Phys. 2017. Vol. 62. N 12. P. $1869-1876$. DOI: $10.1134 / \mathrm{S} 1063784217120222]$

[10] Mueller M.G., Fornabaio M., Zagar G., Mortensen A. // Acta Mater. 2016. Vol. 105. P. 165-175.

DOI: $10.1016 /$ j.actamat.2015.12.006
[11] Ramnath Venkatraman, John C. Bravman // J. Mater. Res. 1992. Vol. 7. N 8. P. 2040-2048.

DOI: https://doi.org/10.1557/JMR.1992.2040

[12] Tsuchiya T., Inoue A., Sakata J. // Sensors and Actuators. 2000. Vol. 82. P. 286-290. DOI: $10.1016 /$ S0924-4247(99)00363-5

[13] Sharpe W.N., Pulskamp J., Gianola D.S., Eberl C., Polcawich R.G., Thompson R.J. // Experiment. Mechan. 2007. Vol. 47. P. 649-658. DOI: $10.1007 / \mathrm{s} 11340-006-9010-\mathrm{z}$

[14] Jinling Yang // J. Microelectromechan. System. 2008. Vol. 17. N 5.

[15] Petersen K. // Proceed. IEEE. 1982. Vol. 70. N 5. P. 420-457.

[16] Tai-Ran Hsu. MEMS and Microsystems: Design and Manufacture. Boston: McGraw-Hill Education, 2002. 436 p.

[17] Marc Madou. Fundamentals of Microfabrication. London: Taylor \& Francis, 1997. 589 p.

[18] Qing An Huang. Micro Electro Mechanical Systems. Singapore: Springer, 2018. 1479 p.

[19] Edwards R.L., Coles G., Sharpe W.N. // Experiment. Mechan. 2004. Vol. 44. N 1. P. 49-54. DOI: $10.1007 / b f 02427976$

[20] Tsuchiya T., Sakata J., Taga Y. // MRS Proceedings. 1998. Vol. 505. P. 285-290. DOI:10.1557/proc-505-285

[21] Ozaki T., Koga T., Fujitsuka N., Makino H., Hohjo H., Kadoura H. // Sensors Actuators A-Physical. 2018. Vol. 278. P. 48-59. DOI: 10.1016/j.sna.2018.05.034

[22] Vayrette R., Raskin J.-P., Pardoen T. // Eng. Fract. Mechan. 2015. Vol. 150. P. 222-238.

[23] Boyce B.L., Grazier J.M., Buchheit T.E., Shaw M.J. // J. Microelectromech. Syst. 2007. Vol. 16. N 2. P. 179-190.

[24] Kaiser B., Drabe C., Graßhoff T., Conrad H., Schenk H. // J. Micromech. Microeng. 2015. Vol. 25. DOI: 10.1088/09601317/25/8/085003

[25] Sharpe W.N., Bagdahn J. // Mechan. Mater. 2004. Vol. 36. N 1-2. P. 3-11. DOI: 10.1016/s0167-6636(03)00027-9

[26] Sharpe W.N., Turner K.T. // FATIGUE 99 - Proceedings of the Seventh International Fatigue Congress. 1999. P. 18371844 . 